\title{
Maternal and Perinatal Prognosis of the Cesarean at Chu Point G, Bamako, Mali
}

\author{
Coulibaly Ahmadou ${ }^{*}$, Seydou Z. Dao ${ }^{2}$, Cissouma Assétou ${ }^{3}$, Sima Mamadou ${ }^{1}$, \\ Kanté Ibrahim Ousmane ${ }^{1}$, Mamadou S. Traoré1, Koné Konimba ${ }^{1}$, Diarra Drissa ${ }^{1}$, \\ Sissoko Hamadi ${ }^{4}$, Théra Thiounkani ${ }^{1}$, Traore Youssouf ${ }^{5}$
}

\author{
${ }^{1}$ Obstetric Gynecology Department of the University Hospital Center (CHU) Point G, Bamako, Mali \\ ${ }^{2}$ Obstetric Gynecology Department of the Reference Health Center of Commune II, Bamako, Mali \\ ${ }^{3}$ Pediatric Department of Sikasso Hospital, Sikasso, Mali \\ ${ }^{4}$ Obstetric Gynecology Service of the Reference Health Center of Commune III, Bamako, Mali \\ ${ }^{5}$ Obstetric Gynecology Department of the University Hospital (CHU) Gabriel Touré, Bamako, Mali \\ Email: *coulimpewo@yahoo.fr
}

How to cite this paper: Ahmadou, C., Dao, S.Z., Assétou, C., Mamadou, S., Ousmane, K.I., Traoré, M.S., Konimba, K., Drissa, D., Hamadi, S., Thiounkani, T. and Youssouf, T. (2021) Maternal and Perinatal Prognosis of the Cesarean at Chu Point G, Bamako, Mali. Open Journal of Obstetrics and Gynecology, 11, 1461-1469. https://doi.org/10.4236/ojog.2021.1111136

Received: September 24, 2021

Accepted: November 8, 2021

Published: November 11, 2021

Copyright $\odot 2021$ by author(s) and Scientific Research Publishing Inc. This work is licensed under the Creative Commons Attribution International License (CC BY 4.0)

http://creativecommons.org/licenses/by/4.0/ (c) (i) Open Access

\begin{abstract}
Objective: In light of numerous obstetric evacuations to the Point G University Hospital and taking into account the practice of cesarean section for many years in the service, it seemed necessary to us to make our contribution to the study of cesarean section by putting emphasis on maternal and perinatal prognosis in the Obstetric Gynecology Department of the Point G university hospital. Method and materials: We conducted a retrospective cross-sectional study in the Gynecology and Obstetrics Department of the Point G University Hospital, from January 01, 2018 to December 31, 2018. The Point G University Hospital is a 3rd level center of reference in the field of obstetrics in Mali. There is no neonatal ward. The study included all women who gave birth in the gynecology and obstetrics department during the study period. All prophylactic and emergency Caesarean section records during the period in which management took place in the ward were included. The records of patients who had a prophylactic or emergency cesarean section in other health facilities and non-usable records were not included. Data were collected using a pre-established survey form. The variables analyzed were socio-epidemiological, clinical and prognostic. Data were analyzed using IBM SPSS software version 16.00 . The Chi2 test and Fischer's exact test were used to highlight risk factors. The significance level retained was $\mathrm{p}<0.05$. Operational definition: Nulliparous: A woman who has never given birth; Primipara: A woman who gave birth once; Pauciparous: A woman who has a number of deliveries between two and three; Multiparous: A woman who has a delivery count of between four and six pregnancies; Large multipara: A woman who has given birth more than six times.
\end{abstract}


Results: We recorded 608 deliveries by cesarean section out of a total of 1573 deliveries, i.e. a rate of $38.6 \%$. The majority of caesarized patients were between 20 and 29 years old or $41.94 \%$, the average age was 26 years old. Out-of-school patients were the most represented, or $44.41 \%$. They were pauciparous in $34.4 \%$ of cases. The pregnant majority had performed at least 04 antenatal consultations, or $68.91 \%$. In $74,51 \%$ of the cases the patients carried a pregnancy estimated to term. Cesarean section was performed urgently in $85.36 \%$ of cases and eclampsia crisis was the most common maternal indication, or $27.97 \%$ among the 379 cases. We recorded 10 maternal deaths or $1.64 \%$. The bleeding disorder was responsible for half of our deaths, or $50 \%$, from retro-placental hematoma. The fetal prognosis was dominated by neonatal distress with $19.08 \%$ of cases. We recorded 101 cases of stillbirths, or $16.61 \%$, and 23 cases of early neonatal death, or $3.78 \%$. Our study found a statistically significant relationship between the type of cesarean section and neonatal death with Fisher's exact test $=27.772, \mathrm{P}<0.0001$.

\section{Keywords}

Cesarean Section, Frequency, Maternal and Perinatal Prognosis

\section{Introduction}

Cesarean section is an obstetric act that saves the newborn and its mother in certain situations. This useful act is only justified if its indication is correctly stated [1]. As early as 1986, with the initiative "for a safer motherhood", the World Health Organization (WHO) recommended that the monitoring of childbirth and the early detection of obstructed labor be selected as one of the most important approaches to reduce maternal mortality [2]. Thus, the proposal to perform a caesarean section to continuously improve the quality of obstetric care responds to these priorities. Cesarean section rates have increased over the past 20 years in the majority of industrialized countries where the surgical technique is perfectly mastered. A 2018 study shows that the global Caesarean section rate has climbed by nearly $10 \%$ in 15 years, with 15 countries where the Caesarean birth rate exceeds 40\% [3]. Despite advances in obstetric surgery, anesthesia, resuscitation, the advent of antibiotic therapy and asepsis, maternal deaths are even more frequent in Africa, especially in Mali. According to demographic and health survey in Mali fifth edition (EDSM V) [4], maternal deaths account for $32 \%$ of all deaths of women aged 15 to 49 . The percentage of female deaths that are "maternal" varies with age irregularly, with peak levels of $28 \%$ at $25-29$ years, $65 \%$ at $30-34$ and $32 \% 35-39$. The high rate of maternal deaths at the middle ages 25 - 39 is consistent with fertility levels since it is at these ages that fertility is the highest [4]. Nowadays, patients normally need a caesarean section, prophylactic drugs are often lost to follow-up in late pregnancy and do not return until early labor. This exposes them to a high risk of maternal and pe- 
rinatal morbidity and mortality. In the light of numerous obstetric evacuations to the Obstetric Gynecology Department of the Point G University Hospital and taking into account the practice of the caesarean section for many years in the service, it seemed necessary to us to make our contribution to the study of the caesarean section by putting the emphasis on maternal and perinatal prognosis in the gyneco-obstetrics department. The objectives of this study were to determine the frequency of cesarean section during the study period, determine the socio-demographic profile of the patients, and finally determine the maternal and perinatal prognosis.

\section{Materials and Methods}

We conducted a retrospective cross-sectional study in the gynecology and obstetrics department of the Point G University Hospital, from January 01, 2018 to December 31, 2018. The Point G University Hospital is a 3rd level center of reference in the field of obstetrics in Mali. There is no neonatal ward. The study included all women who gave birth in the gynecology and obstetrics department during the study period. All prophylactic and emergency Caesarean section records during the period in which management took place in the ward were included. The records of patients who had a prophylactic or emergency cesarean section in other health facilities and non-usable records were not included. Data were collected using a pre-established survey form. The variables analyzed were socio-epidemiological, clinical and prognostic. Data were analyzed using IBM SPSS software version 16.00. The Chi2 test and Fischer's exact test were used to highlight risk factors. The significance level retained was $\mathrm{P}<0.05$.

\section{Operational definition:}

Nulliparous: a woman who has never given birth.

Primipara: a woman who gave birth once.

Pauciparous: a woman who has a number of deliveries between two and three.

Multiparous: a woman who has a delivery count of between four and six pregnancies.

Large multipara: a woman who has given birth more than six times.

\section{Results}

Frequency: During the study period (January 1, 2018 to December 31, 2018), we recorded 608 cesarean deliveries out of a total of 1573 deliveries, or a rate of $38.6 \%$.

\section{Sociodemographic and clinical characteristics:}

The majority of our caesarized patients were between 20 and 29 years old or $41.94 \%$, the average age was 26 years with extremes of 14 and 45 years. Out-ofschool patients were the most represented, i.e. $44.41 \%$. They were pauciparous in $34.4 \%$ of cases. The majority of pregnant women had performed at least 04 antenatal consultations, or $68.91 \%$. In $74.51 \%$ of cases, the patients carried a pregnancy estimated to be term (Table 1). Cesarean section was performed 
Table 1. Sociodemographic and clinical characteristics.

\begin{tabular}{|c|c|c|}
\hline Characreristics & Effective & Frequency (\%) \\
\hline \multicolumn{3}{|l|}{ Age range } \\
\hline [14 years - 20 years [ & 137 & 22.53 \\
\hline [20 years - 30 years [ & 255 & 41.94 \\
\hline [30 years -40 years [ & 196 & 32.24 \\
\hline [ 40 years - 45 years] & 20 & 3. 29 \\
\hline \multicolumn{3}{|l|}{ Education level } \\
\hline Out of school & 270 & 44.41 \\
\hline Primary & 91 & 14.97 \\
\hline Secondary & 201 & 33.06 \\
\hline Superior & 46 & 7.57 \\
\hline \multicolumn{3}{|l|}{ Parity } \\
\hline Nulliparous & 199 & 32.7 \\
\hline Primipara & 110 & 18.1 \\
\hline Pauciparous & 209 & 34.4 \\
\hline Multiparous & 69 & 11.3 \\
\hline Large multipara & 21 & 3.5 \\
\hline \multicolumn{3}{|l|}{ Prenatal consultation (CPN) } \\
\hline No CPN & 86 & 14.14 \\
\hline$[1-3]$ & 103 & 16.94 \\
\hline [4 and over[ & 419 & 68.91 \\
\hline \multicolumn{3}{|c|}{ Age of pregnancy in Week of amenorrhea } \\
\hline Less than 37 & 150 & 24.67 \\
\hline Between 37 and 42 & 453 & 74.51 \\
\hline Greater than 42 & 5 & 0.82 \\
\hline
\end{tabular}

urgently in $85.36 \%$ of cases and eclampsia crisis was the most common maternal indication, or $27.97 \%$ among the 379 cases (Table 2).

\section{Maternal and perinatal prognosis of cesarean section}

We recorded 10 maternal deaths or $1.64 \%$. The bleeding disorder was responsible for half of our deaths, or 50\%, from retro-placental hematoma (Table 3 ). We found a statistically significant relationship between neonatal complications and mode of admission with $\mathrm{P}<0.05$ (Table 4). The fetal prognosis was dominated by neonatal distress with $19.08 \%$ of cases. We recorded 101 cases of stillbirths, or $16.61 \%$, and 23 cases of early neonatal death, or $3.78 \%$ (Table 5). We found a statistically significant relationship between type of cesarean section and neonatal death with Fisher's exact test $=27.772$; $\mathrm{P}<0.0001$ (Table 6). We found a statistically significant relationship between the type of caesarean section and neonatal death with $\mathrm{P}<0.05$. 
Table 2. Type of caesarean section and indications.

\begin{tabular}{lcc}
\hline Type of cesarean and indications & Number of patients & Frequency (\%) \\
\hline Type of cesarean & 519 & \\
Urgent & 89 & 85.36 \\
Prophylactic & & 14.64 \\
\hline Indication & 26 & \\
Pelvic abnormality & 1 & 6.86 \\
Asthma attack & 2 & 0.26 \\
History of vesico-vaginal fistula cure & 2 & 0.53 \\
History of uterine prolapse cure & 2 & 0.53 \\
History of uterine rupture & 5 & 0.53 \\
Heavy obstetric history & 1 & 1.32 \\
Disseminated intravascular coagulation & 12 & 0.26 \\
vaso-occlusive crisis & 32 & 3.17 \\
Pelvic fetal disproportion & 14 & 8.44 \\
Dynamic dystocia/scarred uterus & 106 & 3.69 \\
Eclampsia & 45 & 27.97 \\
Preeclampsia & 3 & 11.87 \\
Elderly primipara & 2 & 0.79 \\
Retinopathy sickle cell & 16 & 0.53 \\
Septicemia & 30.26 \\
Pre-uterine rupture syndrome & & 20.84 \\
Scarred uterus/shruken bony pelvis limit & & \\
Multicicatricial uterus & & \\
\hline & & \\
\hline
\end{tabular}

Table 3. Distribution of patients by cause of death.

\begin{tabular}{lcc}
\hline \multicolumn{1}{c}{ Causes of maternal death } & Number & Frequency (\%) \\
\hline Decompensated anemia (Blood not available) & 2 & 20.00 \\
State of eclamptic illness & 2 & 20.00 \\
Hellp syndrome & 1 & 10.00 \\
Bleeding disorders & 5 & 50.00 \\
Total & 10 & 100
\end{tabular}

Table 4. Distribution of neonatal complications by mode of admission.

\begin{tabular}{lccccccc}
\hline \multirow{2}{*}{ Mode of admission } & \multicolumn{3}{c}{ Neonatal complications } \\
\cline { 2 - 7 } & \multicolumn{2}{c}{ Yes } & \multicolumn{3}{c}{ No } & \multicolumn{2}{c}{ Total } \\
\cline { 2 - 7 } & Number & $\%$ & Number & $\%$ & Number & $\%$ \\
\hline Come from herself & 38 & 6.25 & 65 & 10.69 & 103 & 16.94 \\
Référée & 39 & 6.41 & 146 & 24.01 & 185 & 30.43 \\
\hline
\end{tabular}


Continued

\begin{tabular}{llllllc}
\hline Evacuated & 120 & 19.74 & 200 & 32.89 & 320 & 52.63 \\
Total & 197 & 32.40 & 411 & 67.60 & 608 & 100 \\
\hline
\end{tabular}

Pearson's chi-square $=15.571 ; \mathrm{ddl}=2 ; \mathrm{P}<0.0001$.

Table 5. Distribution of newborns according to the nature of the complications.

\begin{tabular}{lcc}
\hline \multicolumn{1}{c}{ Nature of Neonatal Complications } & Number & Frequency (\%) \\
\hline Neonatal distress & 116 & 19.08 \\
Prematurity & 32 & 5.26 \\
Neonatal distress & 23 & 3.78 \\
Respiratory distress & 7 & 1.15 \\
Others & 19 & 3.13 \\
No complications & 411 & 67.6 \\
Total & 608 & 100.0 \\
\hline
\end{tabular}

Table 6. Distribution of fetal prognosis by type of cesarean section.

\begin{tabular}{lccccccc}
\hline \multirow{2}{*}{ Fetal prognosis } & \multicolumn{5}{c}{ Type of Cesarean section } \\
\cline { 2 - 8 } & \multicolumn{2}{c}{ Urgent } & \multicolumn{2}{c}{ Prophylactic } & \multicolumn{2}{c}{ Total } \\
\cline { 2 - 8 } & Number & $\%$ & number & $\%$ & Number & $\%$ \\
\hline Vivant & 397 & 65.30 & 87 & 14.31 & 484 & 79.61 \\
Mort-nés & 100 & 16.45 & 1 & 0.16 & 101 & 16.61 \\
Décès précoce & 22 & 3.62 & 1 & 0.16 & 23 & 3.78 \\
Total & 519 & 85.36 & 89 & 14.64 & 608 & 100 \\
\hline
\end{tabular}

Fisher's exact test $=27.772 ; \mathrm{P}<0.0001$.

\section{Discussion}

Between January 1, 2018 and December 31, 2018, we recorded 608 cases of caesarean sections out of a total of 1573 deliveries, i.e. a frequency of $38.6 \%$. Our cesarean rate is high compared to the optimal interval set by WHO. This could be explained by the fact that the Point G University Hospital is considered to be the 3rd level reference center and that the majority of these patients have an indication for cesarean section. The study by Coumaré S. [5], Wologueme D. [6], Ganaba S. [7], CT Cissé and col [8], obtained respectively 29.35\%; 28.29\%; $12.44 \%$ and $11.2 \%$ cesarean section rate. On the other hand, Kadima Mutomba C. and col [9] and Tshabu-Aguèmon C. [10] obtained significantly higher rates, $85.53 \%$ and $57.26 \%$.

Cesarean section was performed urgently in $85.36 \%$ of cases and eclampsia crisis was the most common maternal indication, or $27.97 \%$ among the 379 cases. Sylla Cheikna [11] found $46.15 \%$ of cesarean sections performed in emergency versus $53.85 \%$ of prophylactics. As for the indication for cesarean section, 
CT Cissé [8], found pelvic fetal disproportion, placenta previa and dystocia at $41.4 \%$.

In our study, the 20 to 29 year age group was the most represented at $41.9 \%$ and the average age was 26 years with extremes of 14 and 45 years. This is the rule in the studies of Wologueme D., who finds an age group of 20 to 29 years [6]; Sylla Cheickna [11] observe a mean age of 27.41 plus or minus 5.84 with extremes of 14 to 40 years; CT Cissé [8] finds as an average age 26 years [8]; at the Mohamed VI University Hospital in Marrakech, Imane T the 20 to 29 age group was the most represented [12]. Indeed this is explained by the fact that this age group constitutes the population group in full genital activity. In our study, housewives represented $65.13 \%$ of Caesarean sections, this same tendency is found by Korenzo M., i.e. 74.3\% [13]. Out-of-school women were $44.41 \%$. The majority of Caesarized women were married, or $93.1 \%$. This predominance of married women is corroborated by most studies: Ganaba S 92.3\% [7] and Tamboura B 97\% [14] because it is they who lead a regular sexual life.

The majority of our patients had an estimated gestational age at term, or $75.33 \%$. Most of our pregnant women have been consulted at least once. More than half had benefited from at least 4 ANC, or $68.91 \%$. These results differ from those found by Korenzo M. [14] and Dramé M. [15], or 56.7\% and $26.7 \%$ respectively. Unlike Sylla Cheikna [11] who observed $100 \%$ of patients having benefited from at least 4 prenatal consultations.

We recorded 181cases of complications associated with cesarean section, i.e. $29.77 \%$, almost all of which were with emergency cesarean section, or $28.62 \%$. Unlike Kadima Mutombo. C which found $97.37 \%$ of patients with a good prognosis. Ten (10) cases of maternal death were observed, or a death rate on cesarean section of $1.64 \%$. All maternal deaths occurred in the postoperative period, the main cause of which was represented by the coagulation disorder $50 \%$ and state of eclamptic disease $20 \%$. These deaths could be avoided if the availability of blood products was ensured. CT Cissé [8] finds the same rate in Dakar 1.4\%. Unlike AB Adama-Hondegla [16] who found a low rate of $3.2 \%$ and Tshabu-Aguèmon $\mathrm{C}$ [10] a higher rate of 58.69\%.

Among the 608 cesarean sections performed in our study, we recorded $16.61 \%$ stillbirths and $3.78 \%$ early neonatal deaths. The majority of the causes of these deaths were due to respiratory distress and prematurity, respectively $52.17 \%$ and 43.48\%. Sylla Cheickna et al. found 30\% perinatal death [11]; Kadima Mutombo [9] 38.84\% perinatal mortality, Pete Yaïch D Cesar [17] 11.6\% early neonatal death and Tshabu-Aguèmon C [10] 15, 44\% perinatal mortality. Neonatal complications were related to the mode of admission. In fact, among the 320 evacuated patients, we recorded $19.74 \%$ neonatal complications $(n=120)$, unlike those who were referred cold 6.41\%, $(\mathrm{n}=39)$ and the appearances of itself 6 , $25 \%(\mathrm{n}=38)$ : Pearson's chi-square $=15.571$, with $\mathrm{P}<0.0001$. Similarly, Ouédraogo C. [18] according to a study carried out at the Yalgado Ouédragogo Hospital in Ouagadougou on the quality of the cesarean section. The perinatal 
mortality rate was $15.9 \%$ this rate was significantly higher for emergency evacuated women $(23.5 \%)$ than non-evacuated women $(3.8 \%)$, relative risk $=6.2$ and $\mathrm{P}<10$.

\section{Conclusion}

This study shows that cesarean section in our working conditions is coupled with high maternal and perinatal morbidity and mortality. The risk factors identified are largely avoidable, especially rightly or wrongly attributed to the operation masking ipso facto the often irrational circumstances of its practice.

\section{Conflicts of Interest}

No conflict of interest regarding the publication of this article.

\section{References}

[1] Sepou, A., Yanza, M.C., Nguembi, E., et al. (2000) Study of 299 Cases of Practical Caesarean Sections at the Bangui Community Hospital (Central African Republic). Black African Medicine, 47, 13-18.

[2] World Health Organization (1986) Maternal Mortality. Remove Women from the Fetal Gear. WHO Chronicle, 40, 193-202.

[3] Boerma, T., Ronsmans, C., Melesse, D.Y., Barros, A.J.D., Barros, F.C., Juan, L., et al. (2018) Global Epidemiology of Use of and Disparities in Caesarean Sections. The Lancet, 392, 1341-1348. https://doi.org/10.1016/S0140-6736(18)31928-7

[4] Republic of Mali (2014) Mali Demographic and Health Survey (EDSM V) 2012-2013. Planing and Statistics Unit, National Institute of Statistics, INFO-STAT and ICF International, Bamako, 206. https://dhsprogram.com/pubs/pdf/fr286/fr286.pdf

[5] Coumaré, S. (2019) Emergency Cesarean versus Prophylactic Cesarean Section: Maternal-Fetal Prognosis at the Dioila Referral Health Center. Med Thesis, University of Science Technical and Technologies De Bamako, Mali.

[6] Ouologueme, D. (2018) Cesarean Section at the Markala Referral Health Center. Med Thesis, University of Science Technical and Technologies De Bamako, Bamako.

[7] Ganaba, S. (2018) Maternal Complications of Caesarean Section at the "Kalaban Coro" Referral Health Center. Med Thesis, University of Science Technical and Technologies De Bamako, Bamako.

[8] Cisse, C.T., Andriamady, C., Faye, O., Diouf, A., Bouillin, D. and Diadhiou, F. (1995) Indications and Prognosis of Cesarean Sections at the Dakar University Hospital Center. Journal de Gynécologie, Obstétrique et Biologie de la Reproduction, 24, 194-197. https://pubmed.ncbi.nlm.nih.gov/7782593/

[9] Kadima Mutombo, V.S., Mumba Mukandila, T.O. and Biayi Mikenji, J. (2015) Profile and Prognosis of Obstetrical Emergencies in the Labor Ward of the Bonzola Maternity Hospital in Mbujimayi. Mali Medical, 30, 65-73.

[10] Tshabu-Aguèmon, C., Denakpo, J., Adisso, S., Mampassi, E. and de Souza, J. (2012) Maternal and Perinatal Mortality Linked to Obstetric References to the C.U.G.O. of the CNHU-HKM in Cotonou. African Journal of Anesthesioly and Emergency Medicine, 17, 37-43. https://web-saraf.net/Mortalites-maternelle-et.html

[11] Cheickna, S., Oumar, T.S., Alassane, T., Alou, S., Saleck, D., Tall, S., Belco, T., et al. 
(2020) Materno-Fetal Prognosis of Prophylactic Cesarean Versus Emergency Cesarean Section at the Reference Health Center of Commune V of the District of Bamako. Surgical Science, 11, 329-341.

[12] Imane, T. (2012) The Indications for Cesarean Section, Experience of the Gyneco-Obstetrics Department within the CHU Mohamed VI. Thesis Med, Cadi Ayyad, Morocco.

[13] Korenzo, M. (2015) Study of the Caesarean Section at the Reference Health Center of Commune II (CSRef) of the District of Bamako. Med Thesis, University of Science Technical and Technologies De Bamako, Bamako.

[14] Tamboura, B. (2013) Prophylactic Caesarean Section versus Emergency Caesarean Section at the Reference Health Center of Commune V of the District of Bamako. Thesis Med, University of Science Technical and Technologies De Bamako, Bamako.

[15] Dramé, M. (2012) Contribution to the Study of Caesarean Section in the Reference Health Center of Dioila. Thesis Med, University of Science Technical and Technologies De Bamako, Bamako.

[16] Adama-Hondegla, A.B., Aboubakari, A.S., Dagba, K.E., Fiagnon, K., Bassowa, A and Akpadza, K. (2015) Maternal and Perinatal Prognosis One Year after the Cesarean Section Subsidy at the Sylvanus Olympio, University Hospital Center (CHU) in Lomé. Journal de la Recherche Scientifique de I Université de Lomé, 17, 703-711. https://www.ajol.info/index.php/jrsul/article/view/135094

[17] Cesar, P.Y.D., Ouattara, A., Koffi, N., Abhé Chiaké, Sanou, J., Itéké, F. and Kane, M. (2012) Emergency Cesarean Sections: Maternal-Fetal Prognosis at the Cocody University Hospital in Abidjan. The African Journal of Anesthesiology and Emergency Medicine, 17, 60-65.

[18] Ouédraogo, C., Zoungrana, T., Dao, B., Dujardin, B., Ouédraogo, A., Thieba Blandine, B., et al. (2001) Quality Cesarean Section at the Yalgado Ouedragogo Hospital Center in Ouagadougou. Analysis of the Determinants of 478 Cases Collected in Obstetrics Gynecology's Service. Black African Medicine, 48, 443-451. 